\title{
Behaviour of the F1-region, and $E s$ and spread- $F$ phenomena at European middle latitudes, particularly under geomagnetic storm conditions
}

\author{
PAL BENCZE ( $\left.{ }^{1}\right)$, DALIA BUREŠOVÁ $\left({ }^{2}\right)$, JAN LAŠTOVIČKA $\left({ }^{2}\right)$ and FERENC MÄRCZ $\left({ }^{1}\right)$ \\ (') Geodetic and Geophysical Research Institute, Hungarian Academy of Sciences, Sopron, Hungary \\ $\left.{ }^{(}{ }^{2}\right)$ Institute of Atmospheric Physics, Academy of Sciences of the Czech Republic, Prague, Czech Republic
}

\begin{abstract}
Knowledge of the ionospheric electron density distribution and its fluctuations is essential for predicting ionospheric characteristics for radio wave propagation and for other applications such as satellite tracking, navigation, etc. Geomagnetic storm is the most important source of the ionisation density perturbations. Recent studies of the F1-region electron density distribution revealed systematic seasonal and latitudinal differences in the $F 1$-layer response to geomagnetic storm. At European higher middle latitudes no significant effect has been observed in summer and spring at heights of 160-190 km, whereas well-pronounced depression appears in winter and late autumn at least at 180$190 \mathrm{~km}$. A brief interpretation of this finding will be presented. On the other hand, the pattern of the response of the ionosphere at $F 1$-layer heights does not seem to depend on the type of response of $F 2$-layer $(f o F 2)$ or on solar activity. Concerning the main types of ionospheric irregularities sporadic $E$ and spread- $F$, it has been found that considering sporadic $E$-layers as thin diffraction screen, it may be modelled for propagation of radio-waves by the determination of the temporal variation of foEs representing in ionograms the mean ion density of «patches» of increased ion density embedded in the Es-layer. Spectrum of these variations indicates the mean period of the variations, which multiplied by the wind velocity gives the mean distance of patches, that is, the mean distance between the screen points. In case of spread- $F$, it has been found that irregularities causing spread- $F$ are mostly due to plasma instabilities, though the role of travelling ionospheric disturbances may be not entirely neglected.
\end{abstract}

\subsection{INTRODUCTION}

The F1-region and its response to geomagnetic storm-induced disturbances has been studied much less than the F2- and $E$-regions and their response to geomagnetic storms, partially due to lower importance of the $F 1$-region for ionospheric propagation of radio waves and also due to substantially weaker geomagnetic storm effects on the $F 1$-region electron density compared with those in the $F 2$-region (above $200 \mathrm{~km}$ ) and in the lower ionosphere (below about $100 \mathrm{~km}$ ). For instance, the review papers by Buonsanto (1999) and Prölss (1995) did not deal with storm effects on the $F 1$-region at all. Laštovička (1996) reviewed in brief geomagnetic storm effects on the lower ionosphere, middle atmosphere and troposphere. 
However, during geomagnetic storms the $F 1$-region becomes more important for the ionospheric radio wave communications, particularly under the so-called $G$-conditions, when the substantially reduced $F 2$-region is screened by the $F 1$-region and the latter serves as the radio wave reflecting layer. Then the F1-region determines the radio wave propagation conditions. This is the main reason we studied the response of the $F 1$-region to geomagnetic storms in COST 271.

Concerning the study of ionospheric irregularities and their modeling, the aim was to support understanding of anomalies found in relation to terrestrial and transionospheric propagation of radio waves. The trend of development in telecommunication by radio waves is the reduction of transmitter power and the decrease of the wavelength of radio waves. Knowing the characteristics of the propagation medium, i.e. those of the ionosphere and plasmasphere, both efforts led to a decrease of the signal to noise ratio. Ionospheric irregularities were not very significant, till the wavelength of radio waves was much larger than the extent of ionospheric irregularities of about $100 \mathrm{~m}$. Nowadays radio waves in the wavelength band of $0.1 \mathrm{~m}$ and more are used in telecommunication.

We may generally distinguish two main types of ionospheric irregularities, sporadic $E$-layers and the spread- $F$ phenomenon. Both types have been known for a long time due to the vertical sounding of the ionosphere. Now experiences connected to propagation of VHF and UHF waves necessitate the detailed study of these irregularities.

\subsection{GEOMAGNETIC STORM EFFECTS ON THE F1-REGION ELECTRON DENSITY}

Ionisation at the F1-region heights is closely related to neutral composition. Changes in the neutral atmosphere ionisation and photochemical processes play important roles in the $F 1$-region electron density distribution due to the shorter lifetime of free electrons compared with the $F 2$-region. Rishbeth and Garriott (1969) described the photochemical processes in the bottomside ionosphere and placed the transition height between the region dominated by molecular ions $\left(\mathrm{NO}^{+}\right.$and $\left.\mathrm{O}_{2}^{+}\right)$and the region where the atomic ions $\mathrm{O}^{+}$dominate at about $160-200 \mathrm{~km}$.

Significant progress in the analysis of the F1-region behaviour under geomagnetic storm conditions has been made in the last few years within the COST 271 project. Burešová and Laštovička (2001), Burešová et al. (2002a) and Bencze et al. (2002) analysed the effects of a few geomagnetic storms in electron density at $F 1$ heights during daytime, based on data from several European ionosondes. Mikhailov and Schlegel (2003) attempted to systemize the geomagnetic storm effects on the $F 1$-region electron density and gave a physical interpretation to the revealed electron density profile variations using Millstone Hill (middle latitude) and EISCAT (auroral zone) Incoherent Scatter (IS) daytime measurements.

\subsubsection{Seasonal and latitudinal dependence of the geomagnetic storm effects}

An investigation of effects of 35 selected strong geomagnetic storms on the ionosphere at $F 1$ heights over Europe showed that, in general, independent of the sign of the geomagnetic storm effect on the $F$ 2-layer ( $f o F 2$ ), the effect on electron density at the $F 1$ heights at European high middle latitudes has always been negative, if any at all. Another important finding of our studies is the summer/spring versus winter/autumn difference in the effect of strong geomagnetic storms on the daytime F1-region, i.e. an insignificant to moderate effect in summer and spring, respectively, versus an evident decrease of daytime electron density in winter/autumn at higher middle latitudes (Burešová and Laštovička, 2001; Burešová et al., 2002a), as illustrated in fig. 12.1. There is no detectable effect of geomagnetic storm on electron density at $F 1$ heights in the range 160-190 km during summer except for a moderate effect of the super storm of July 2000 at 180-190 km (Burešová, 2002; Burešová et al., 2002b,c). On the other hand, in winter there is a substantial effect on electron density at 190 

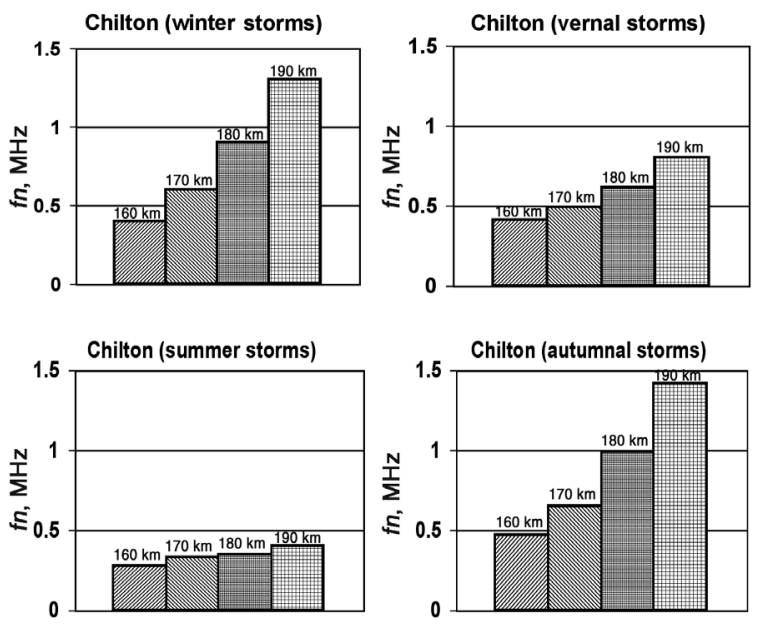

Fig. 12.1. The magnitude of the mean electron density decrease at the fixed $F 1$-region heights (the difference between pre-storm quiet days and the storm main phase at 11:00-13:00 UT) for all analysed 35 geomagnetic storms, which occurred during different seasons, for Chilton.
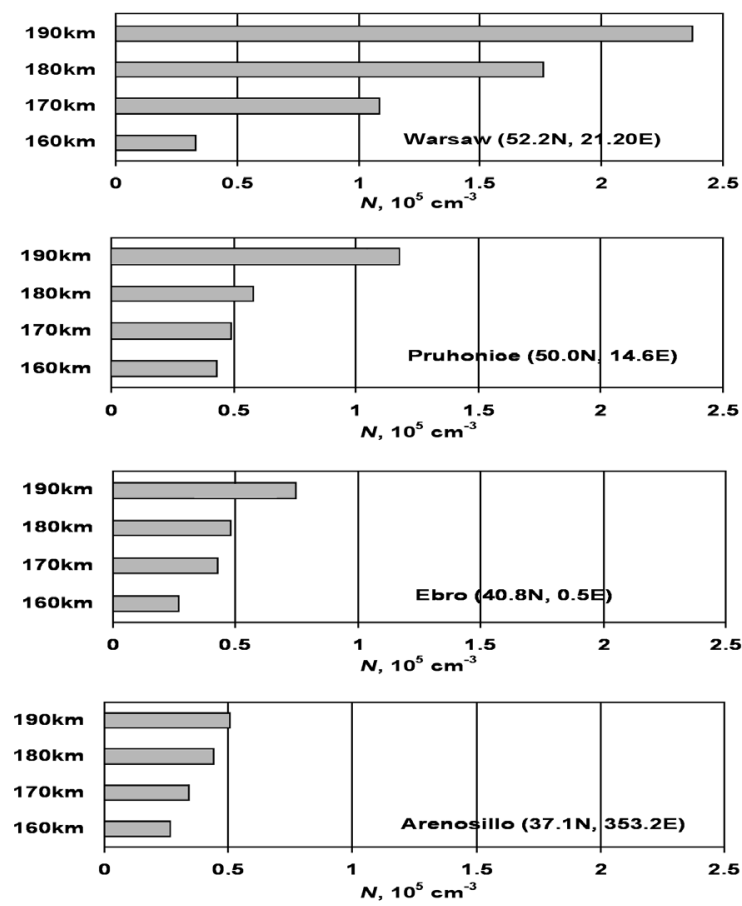

Fig. 12.2. The magnitude of the electron density decrease at the $F 1$-region heights (the difference between prestorm quiet days and the storm main phase at 11:00-13:00 UT) for the storm of February 1998 for Warsaw, Pruhonice, Ebro and Arenosillo. 
$\mathrm{km}$, there is still a well-detectable effect at $180 \mathrm{~km}$, a weak effect at $170 \mathrm{~km}$ and no detectable effect at $160 \mathrm{~km}$ except for the super storm of March-April 2001, which caused substantial changes down to $160 \mathrm{~km}$. The winter effect consists in a significant depletion of electron density during the main phase of the storm. Winter in this sense means probably autumn and winter, i.e. months with shorter sunlit periods and higher solar zenith angles.

Observations suggest that the upward motion of the transition height might be an important mechanism responsible for the effects of the geomagnetic storms at the $F 1$-region heights (the electron loss rate is considerably larger below than above the transition height). Using the MSIS-E-90 model Burešová and Laštovička (2003c) for Chilton in 1998 found the transition height to be located above 200 $\mathrm{km}$ in mid-summer and for the rest of the year below $200 \mathrm{~km}$, well below $200 \mathrm{~km}$ in winter. This qualitatively explains the observed summer-winter difference. The absence of a remarkable effect in summer appears to be due to small compositional change in summer, because even the quiet-time transition boundary is above the $F 1$-region.

In summer the regular (solar-induced) and storm-induced meridional winds coincide and the gases with decreased $\mathrm{O} / \mathrm{N}_{2}$ ratio are moved from the high latitudes into middle latitudes. The wintertime background circulation does not allow propagation of compositional disturbance from high latitudes well to lower latitudes and thus diminishes or stops the upward motion of the transition boundary. This is probably the reason we sometimes observe substantial geomagnetic storm effects on the $F 1$ region at higher middle latitudes but not at Ebro and Arenosillo (Burešová et al., 2002b). Figure 12.2 illustrates the decrease in F1-region electron density during February 1998 storm main phase for selected European stations. In general, the F1-region response to geomagnetic storm-induced disturbances at European lower middle latitude is weaker and less regular.

\subsubsection{Dependence of the effects on solar activity}

Burešová and Laštovička (2001) analysed the effect of geomagnetic storms on the $F 1$-region electron density only for events observed under low solar activity conditions. Recently several events observed under higher and high solar activity conditions have been examined (Burešová et al., 2002a; Burešová, 2002; Burešová and Laštovička 2003a,c). The pattern of the geomagnetic storm effects on the $F 1$-region electron density does not appear to change with solar activity (solar cycle).

\subsubsection{F1-region under superstorm conditions}

According to King (1961), the depth of the storm-induced disturbances penetration into the $F 1$-region depends on the magnitude of the geomagnetic storm, but it also depends on the latitude and season. We found the geomagnetic super storms penetrate deeper into the $F 1$-region than the effects of analysed strong storms, as documented by fig. 12.3 (Burešová et al., 2002a). One process, which probably contributes to the deeper penetration of the super storm effects, is the equatorward shift of the auroral zone, which is larger for these super storms. For instance, during the super storm of February 1986, the Pruhonice station was for a couple of hours in the auroral zone (Boska and Pancheva, 1989).

\subsubsection{F1-region intra-hour variability}

15 min sequences of ionograms recorded during the storms of May and November 1997 and September-October 2002 have been used to investigate the bottomside $F$-region intra-hour variability. Figure $12.4 \mathrm{a}-\mathrm{c}$ shows the course of the absolute value of the differences between hourly $N m F 2$ and every 15 min NmF2 obtained during each hour September-October 2002 event. For quiet ionospher- 

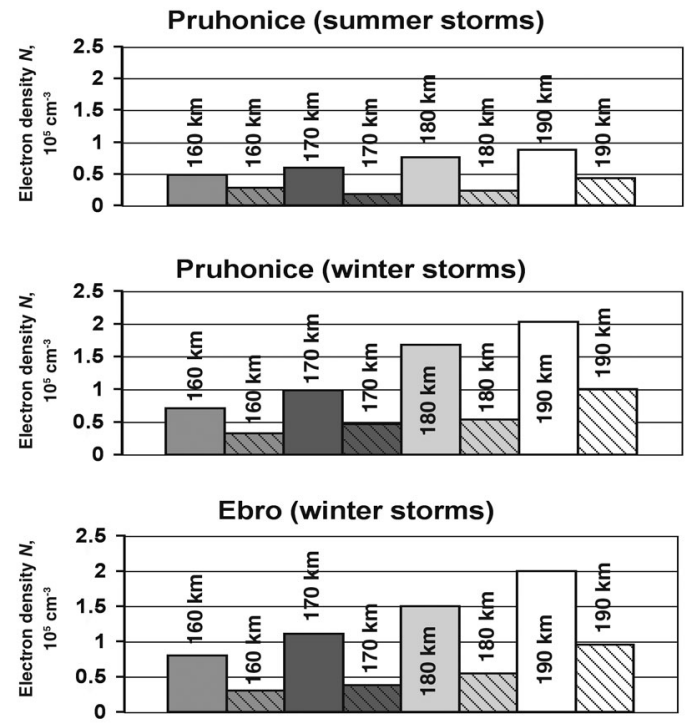

Fig. 12.3. The magnitude of the electron density decrease at the $F 1$-region heights (the difference between prestorm quiet days and the storm main phase at 11:00-13:00 UT) for the super storm of July 2000 versus the May 1997, June 1998, August 1998 strong storms for Pruhonice (top panel) and for the super storm of March/April 2001 versus the strong storms of January 1996, February 1998, March 1998 and November 1998 (middle panel - Pruhonice; bottom panel - Ebro). Full columns - super storms; dashed columns - strong storms.

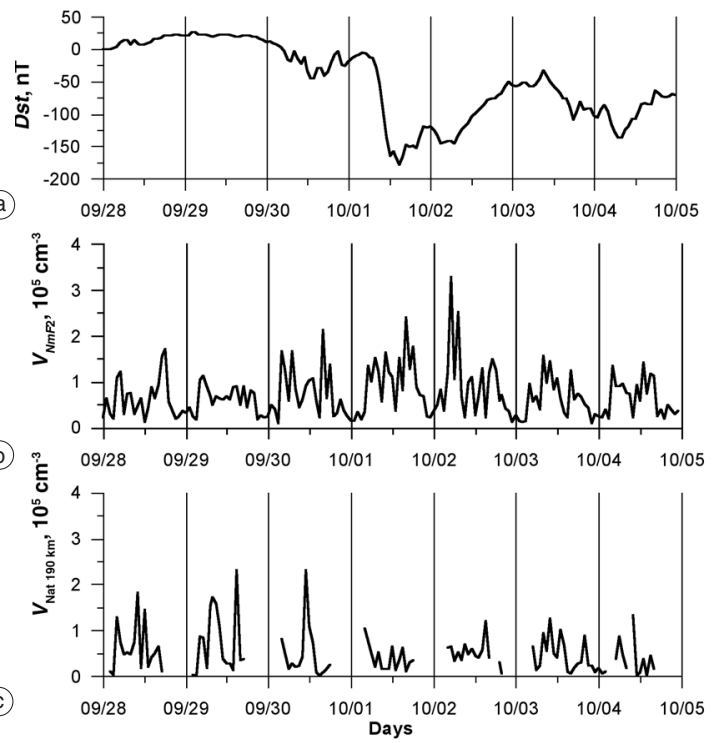

Fig. 12.4. Storm of September-October 2002: a) course of the hourly Dst index; b) course of the differendes between hourly $\mathrm{NmF2}$ and every $15 \mathrm{~min} N m F 2$ obtained during each hour, (c) the same for electron density at $190 \mathrm{~km}$. 
ic conditions these differences are most pronounced near sunrise and sunset, as expected. During ionospheric storms the differences are large and significant also during daytime, particularly for the September-November 2002 event. Figure $12.4 \mathrm{c}$ presents in the same way the electron density intrahour variability for electron density at $190 \mathrm{~km}$ for the same geomagnetic storm. The intra-hour variability during storm maximum days has been found surprisingly small. However, for the SeptemberOctober 2002 the pre-storm, storm onset day and the recovery phase, the intra-hour variability was approximately twice as high as that for May 1997 (Burešová and Laštovička, 2001). Our F1-region results on intra-hour variability are very similar to those shown in fig. 12.4a-c for all other analysed spring and autumn events.

\subsubsection{Height of maximum storm effects}

Figure 12.5 displays the height profile of the effect of a strong geomagnetic storm, which has a maximum well below the maximum of the F2-layer (Burešová and Laštovička 2003b). Inspection of a couple of events showed that such behaviour is typical for storms with the positive phase in foF 2 . Broader investigations of this phenomenon are underway.
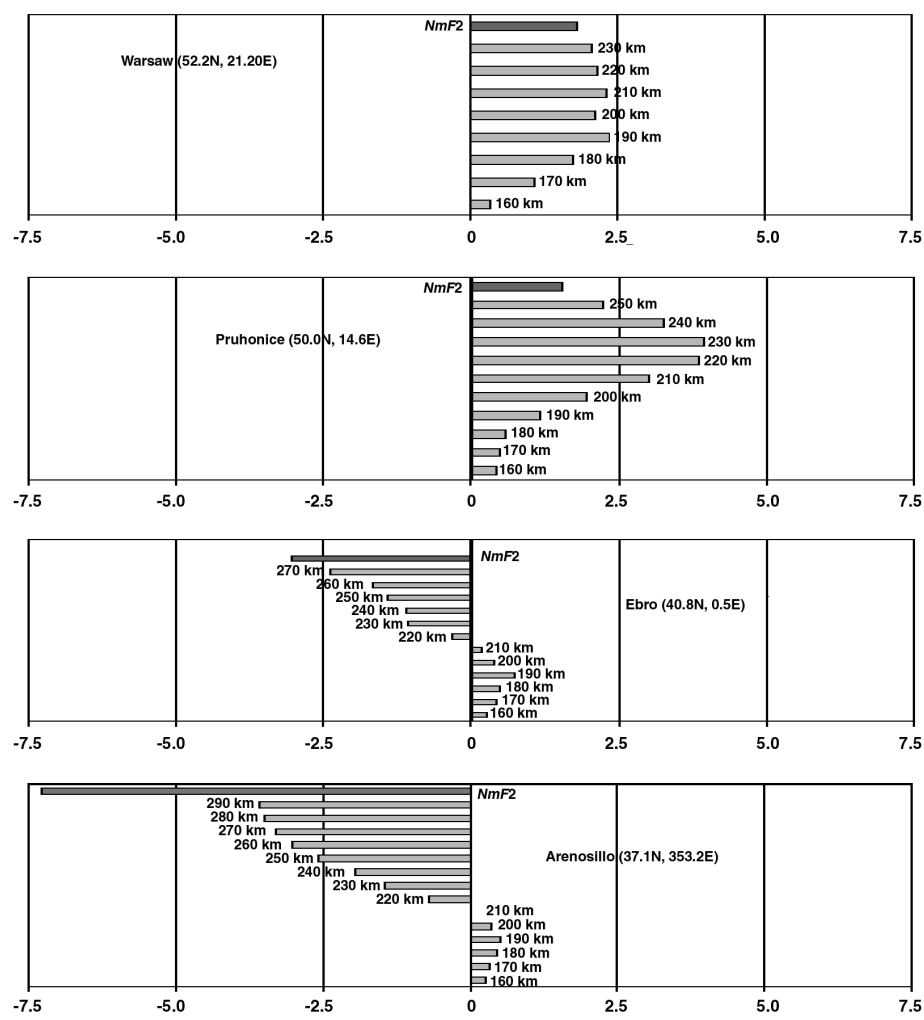

Fig. 12.5. The magnitude of the electron density decrease at $F$-region heights (the difference between pre-storm quiet days and the storm main phase at 11:00-13:00 UT) for the geomagnetic storm of February 1998. 


\subsection{IONOSPHERIC SPORADIC $E$-LAYER}

Investigations carried out in the framework of COST 271 are concentrated to mid-latitudes. It is necessary to emphasize this because the origin of sporadic $E$ - $(E s-)$ layers differs depending on geomagnetic latitude. Considering mid-latitude Es-layers, there is a generally accepted theory, the wind-shear theory of mid-latitude sporadic $E$ (Whitehead, 1961; Axford et al., 1966). According to this theory, it is the vertical shear of the horizontal wind, which changes the vertical distribution of ion (electron) density by the interaction between the wind and the geomagnetic field $(\bar{u} \times \bar{B})$. This force moves ions upwards from that part of the electron density profile where the wind is in a W-E direction and moves ions downwards, from that part of the profile, where the wind has a E-W direction. Thus, ions are concentrated at the height where the zonal wind changes sign. Incoherent scatter and coherent scatter radar measurements have shown that patches of enhanced ion density are embedded in the background ion density of the Es-layer (e.g., Bourdillon et al., 1995; Haldoupis et al., 1996).

\subsubsection{Es parameters}

The Es-layers are characterized by two frequencies, foEs and $f b E s$. foEs is the maximum frequency of radio waves reflected by the $E s$-layer, however, partially transmitting them, while $f b E s$ is the so called blanketing frequency representing that frequency, to which the Es-layer is not transparent for sounding radio waves, it screens the overlying ionosphere. $f b E s$ corresponds to the background ion density, foEs is proportional to the mean ion density of patches. The apparent height $h^{\prime} E s$ may be regarded as the real height of Es-layers, since the ion density in an Es-layer is much higher than below it. Thus, retardation of the sounding radio waves is negligibly small. It has been found there is no change in $h^{\prime} E s$ exceeding the accuracy of ionosonde scaling $(5 \mathrm{~km})$ between the solar activity maximum and minimum (Bencze and Märcz, 2002).

The $f o E s-f b E s$ difference may be considered as a quantity proportional to the transparency of $E s$ layers for radio waves (Bencze, 1983). It may be shown that transparency of $E s$-layers is related to the wind shear. In fig. 12.6 the seasonal variations of transparency and wind shear are plotted showing a summer maximum in both cases.

\subsubsection{Modeling of $E s$-layers for radio propagation}

In case of modeling Es-layers to study the propagation of radio waves, it is necessary to take into account the structure of these layers. Observations of incoherent scatter radar indicate a structure resembling a diffraction screen from the point of view of radio-wave propagation. This diffraction screen may be identified with a thin diffraction screen, since $E s$-layers represent a thin stratification.

Characteristic of a diffraction screen is its screening constant, which gives the distance between points of the screen. The screening constant may be determined by the vertical sounding of the ionosphere, if soundings are made frequently enough. Three minute ionograms are already enough for determination of the spectrum of the variation in foEs. Temporal variation of foEs indicates the spatial distance between patches, that is, between screen points.

Spectrum of distances between patches, constructed for a winter day, when ionospheric soundings were carried out every $3 \mathrm{~min}$, is shown in fig. 12.7. The radio waves of wavelength shorter than about half the double distance between screen points in the thin diffraction screen are influenced by the screen. The figure indicates that the predominant separation of sporadic $E$ patches is only a few kilometres. This result is of importance to the oblique propagation of VHF transmissions over long distances by reflection from sporadic $E$ ionisation (Edwards et al., 1984). It has been sug- 

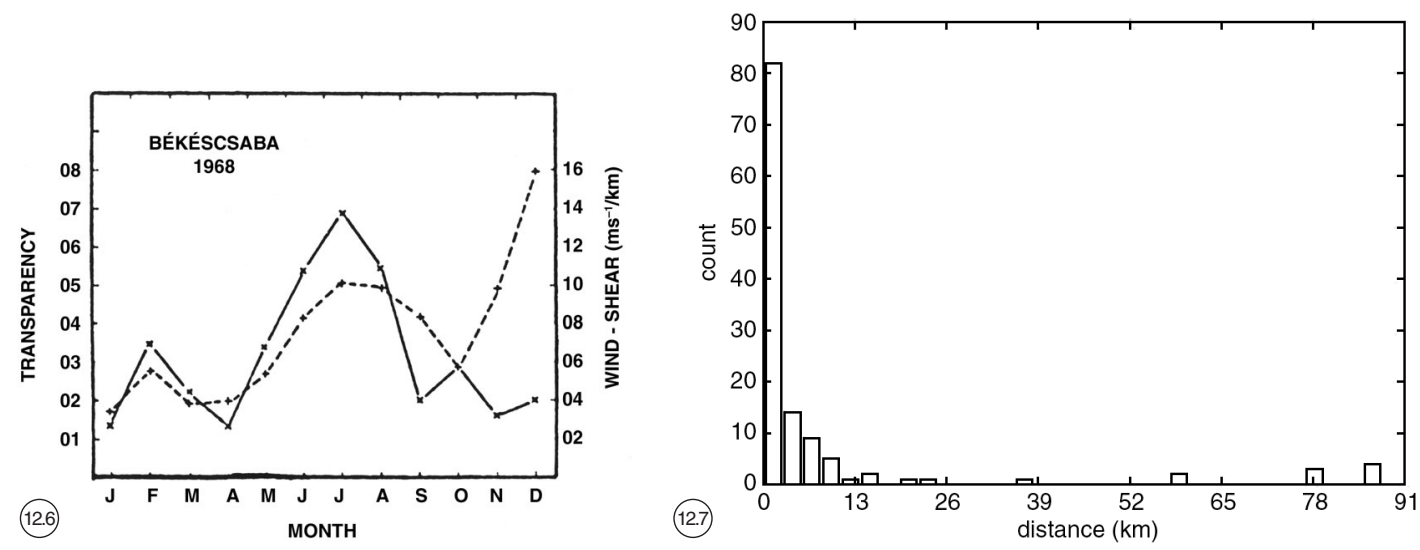

Fig. 12.6. Seasonal variations of transparency of Es-layers and wind-shear (Bencze and Märcz, 2002).

Fig. 12.7. Preliminary spectrum of the distances between patches in sporadic $E$-layers (indicating the distance between screenpoints in case of a thin diffraction screen).

gested that the high, possibly unwanted, signal levels sometimes observed for this propagation mechanism arise from the constructive interference of a few modes propagating by reflection from closely-spaced ionisation patches, in accord with the current result.

\subsection{THE SPREAD-F PHENOMENON}

Scattered echoes have sometimes been observed in the $F$-region on ionograms. These scattered echoes are due to ionospheric irregularities and occur as broadening of the trace marking reflections from the ionosphere along the frequency axis $\left(F\right.$ spread), or along the virtual height axis $\left(h^{\prime}\right.$ spread). Development of ionospheric irregularities producing spread- $F$ occurrence has been attributed to travelling ionospheric disturbances (e.g., Bowman, 1981, 1990). VHF radar measurements indicated the instability origin of spread- $F$ (Fukao et al., 1988). Thus, two different mechanisms exist for the development of spread- $F$ causing irregularities.

\subsubsection{Travelling ionospheric disturbances as source of ionospheric irregularities in the $F$-region at mid-latitudes}

Travelling Ionospheric Disturbances (TID) are classified according to their horizontal wavelength. Large scale TIDs are atmospheric gravity waves with a horizontal wavelength exceeding 1000 $\mathrm{km}-\mathrm{s}$ and vertical wavelength of $400-500 \mathrm{~km}$ and a period longer than about $30 \mathrm{~min}$. Their source is the auroral region. Medium scale TIDs are probably associated with meteorological phenomena. Following Bowman here only large scale TIDs are considered as sources of ionospheric irregularities in the $F$-region. For the investigation of this possibility the following procedure has been developed (Bencze and Bakki, 2002). For the indication of a sudden expansion of the auroral zone and - as a consequence - generation of large scale TIDs, the events have been selected when the AE index is greater than the mean value of AE indices of the five most disturbed days in the corresponding month. The monthly number of these hours has been determined for each hour of the day. Figure 12.8 shows 

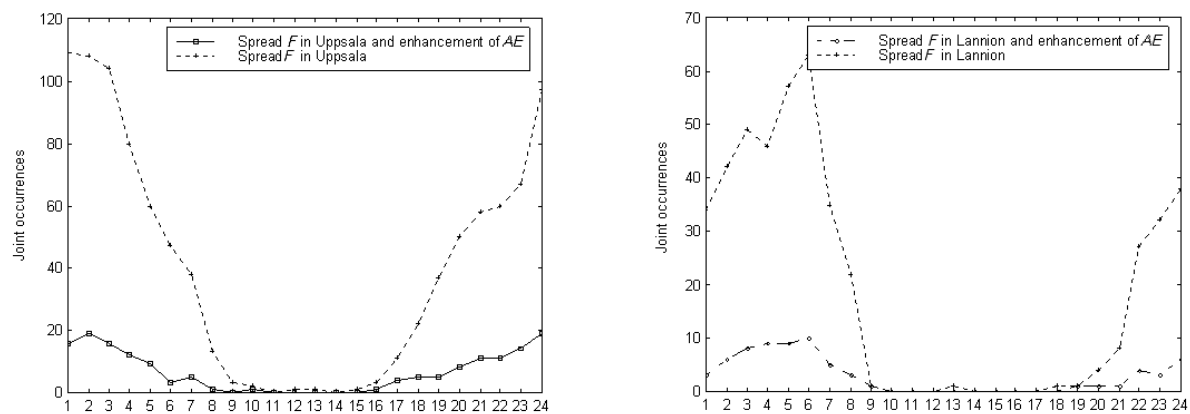

Fig. 12.8. Daily variation of the simultaneous occurrence of spread- $F$ and AE enhancements (Bencze and Bak$\mathrm{ki}, 2002)$.

the daily variations of the simultaneous occurrence of spread- $F$ and enhancements of the AE index for two ionospheric stations, Uppsala at high latitudes $\left(59.8^{\circ} \mathrm{N}\right)$ and Lannion at mid-latitudes $\left(48.45^{\circ} \mathrm{N}\right)$. The daily variation of the simultaneous occurrence of spread- $F$ and $A E$ enhancements indicates a maximum by night. Number of the simultaneous occurrence attains at the time of the morning a maximum $30 \%$ of the total number of spread- $F$ occurrences in Uppsala and $23 \%$ in Lannion. A delay of about $4 \mathrm{~h}$ can be observed between the morning maximum of the simultaneous occurrence of spread- $F$ and $A E$ enhancements at the mid-latitude Lannion station as compared with the high latitude Uppsala station. This delay may be connected with the propagation of travelling ionospheric disturbances from auroral latitudes.

\subsubsection{Plasma instabilities as sources of ionospheric irregularities in the $F$-region at mid-latitudes}

Types of plasma instabilities, which may be effective in the development of spread- $F$ producing ionospheric irregularities at mid-latitudes are the Rayleigh-Taylor, the $\boldsymbol{E} \times \boldsymbol{B}$ and the Perkins instabilities (Kelley, 1989). On the basis of the results obtained in Section 12.4.1 related to travelling ionospheric disturbances as a source of ionospheric irregularities in the $F$-region, instabilities may contribute to the time of the morning maximum by about $70 \%$ to the development of irregularities. Thus, they are the dominant source of irregularities, but it seems that the role of TIDs may not be completely neglected.

\subsubsection{Comparison of the growth rate of plasma instabilities at mid-latitudes}

Connected with study of the spread- $F$ creating irregularities, growth rates of plasma instabilities considered at mid-latitudes are also discussed. Rayleigh-Taylor instability is not considered here, since it is practically limited to low latitudes.

Concerning the $(\bar{E} \times \bar{B})$ instability, its growth rate can be expressed by the equation, neglecting the electrical coupling along field lines (Maruyama, 1990)

$$
\gamma=\frac{\nu_{\perp}}{n_{o}} \cdot \frac{\cos I d n_{o}}{d z}
$$


where $v_{\perp}$ is the drift velocity perpendicular to the geomagnetic field, I is the dip angle and $n_{o}$ stands for the background electron density. For computation of the drift velocity perpendicular to the geomagnetic field, the electric field model of Richmond et al. (1980) was applied, the electron density and its vertical gradient were obtained using the ionospheric model IRI-90. Figure 12.9a,b shows that the growth rate increases with growing vertical electron density gradient, but is also enhanced with increasing latitude. Conditions for the development $(\bar{E} \times \bar{B})$ of instability are given, if an eastward electric field or southward component of the neutral wind occurs in the presence of a vertical electron density gradient. The growth rate of the Perkins instability considering only the dominant term may be written in the form (Perkins, 1973; Klevans and Imel, 1978)

$$
\gamma=\frac{E_{o} \cos I}{B H_{n}} \sin ^{2}(\Theta / 2)
$$

where $E_{o}$ is the ambient electric field, $H_{n}$ is the neutral pressure scale height, $\Theta$ stands for the angle between East and the direction of the electric field $E_{o}$. For calculation of the eastward and northward components of the electric field, for the determination of their resultant and $\Theta$, the electric field model of Richmond et al. (1980) was used. Equation (12.2) shows that the growth rate increases with growing northward electric component by increasing $\Theta$, however, the growth rate is reduced with increasing latitude (fig. 12.9a,b).

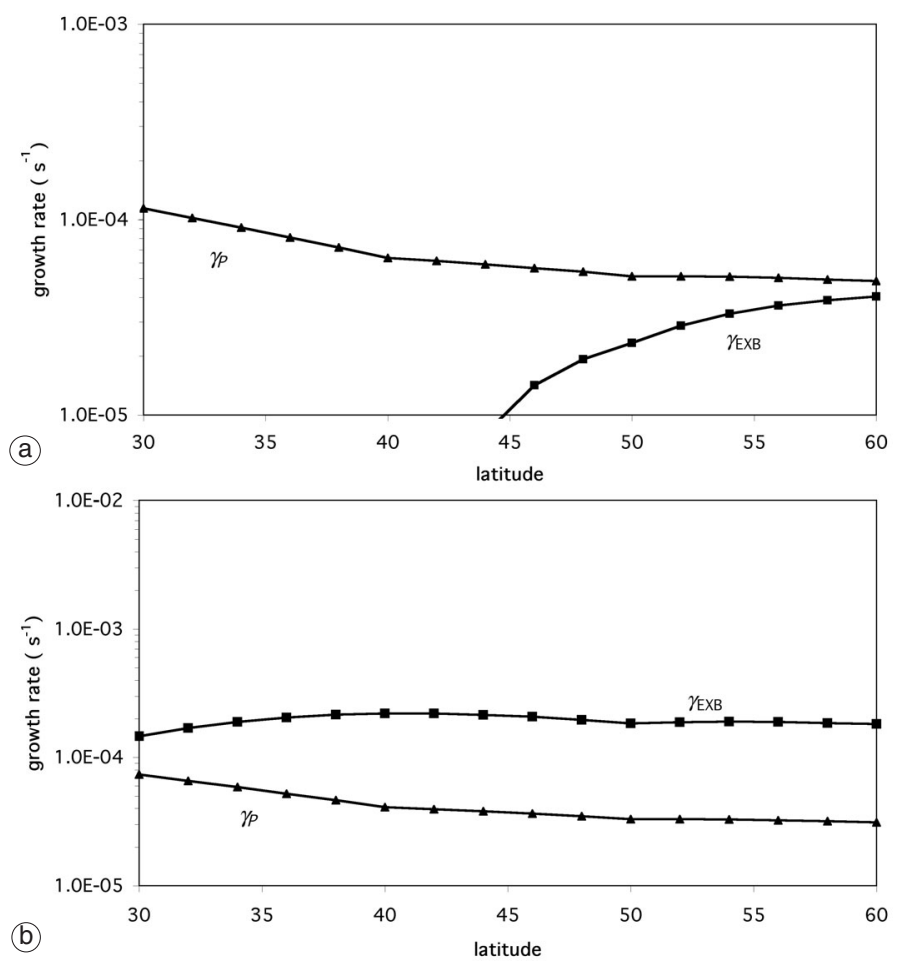

Fig. 12.9a,b. Latitudinal variation of the instability and the Perkins instability. 
Using equations of the growth rates of plasma instabilities responsible for ionospheric irregularities at mid-latitudes, growth rates at $300 \mathrm{~km}$ and in years of minimum solar activity (1976) and maximum solar activity (1979) have been computed and plotted as a function of latitude (fig. $12.9 \mathrm{a}, \mathrm{b})$. The growth rate of the $(\bar{E} \times \bar{B})$ instability is smaller than the growth rate of the Perkins instability.

\subsection{Conclusions}

An investigation of the effects of selected strong geomagnetic storms and super storms on the daytime ionosphere at $F 1$ heights in Europe has been based on electron density profiles inferred from ionograms recorded at the higher middle and lower middle latitude stations Juliusruh, Pruhonice, Chilton, Warsaw, Ebro, Arenosillo and Athens. The four main results are as follows:

1) Independent of the sign of the geomagnetic storm effect on $\mathrm{NmF2}$, the effect on electron density at the $F 1$ heights at European higher middle latitudes has always been negative, if any at all. At European lower middle latitudes, the effects at $F 1$-region heights are weaker and less regular.

2) There is a substantial summer/winter asymmetry of geomagnetic storm effects on the $F 1$-region electron density at European higher middle latitudes. There is no significant effect of geomagnetic storms on electron density at the $F 1$ heights in the range of 160-190 km during the summer half of the year except for the moderate-to-minor effect of the super storm. On the other hand, in the winter half of the year at higher middle latitudes there is a well-pronounced effect of magnitude increasing with height. The winter effect at higher middle latitude consists in a depletion of electron density during the main phase of the storm.

3) The geomagnetic super storm effects penetrate deeper into the $F 1$-region than the effects of strong storms.

4) The pattern of the geomagnetic storm effects on the F1-region electron density does not appear to change with solar activity (solar cycle).

The upward motion of the boundary between the region dominated by molecular ions and the region dominated by atomic ions evidently plays a role in explaining the observed effects.

Study of sporadic $E$-layers and spread- $F$ at mid-latitudes resulted in the following main findings:

1) Concerning the frequency parameters of sporadic E-layers, foEs is considered as a quantity proportional to the mean ion-density of «patches» of increased ion density in the layer. Thus, its temporal variation may indicate the mean periodicity of ion density enhancements, which would show the screenpoints of a thin diffraction screen.

2) Modelling of Es-layers may be based on the mean period of the variation of $f_{o E s}$, if it is multiplied by the wind speed at the corresponding time and height.

3) Using the daily variation of the simultaneous occurrence of spread- $F$ and sudden enhancements of the auroral electrojet index AE indicating the generation of travelling ionospheric disturbances, it has been found that spread- $F$ producing ionospheric irregularities are mainly due to plasma instabilities, though the effect of travelling ionospheric disturbances may not be excluded.

\section{ACKNOWLEDGEMENTS}

Investigations by P.B. and F.M. were supported by the grant TP 121 of the Hungarian Space Office. The work of D.B. and J.L. was supported by grants A3042102 of the Grant Agency of the Academy of Sciences of the Czech Republic and OC.271.10 of the Ministry of Education, Youth and Sports of the Czech Republic. The Hungarian authors thank to Mr. P.A. Bradley and Prof. L. Kersley for useful discussions. 


\section{REFERENCES}

Axford, W.J., D.M. Cunnold and L.J. GleEson (1966): Magnetic field variations in temperate zone sporadic E-layers, Planet. Space Sci., 14, 909-919.

BeNCZE, P. (1983): On the origin of Es transparency, INAG Bull., 40-41, 12.

Bencze, P. and P. BAKKI (2002): On the origin of mid-latitude spread-F, Acta Geod. Geophys. Hung., 37, 409-417.

Bencze, P. and F. MÄrcz (2002): A study of the variation of the transparency of Es-layers, Acta Geod. Geophys. Hung., 37, 227-238.

Bencze, P., D. BuREŠová and J. LAŠTOVIČKa (2002): On the storm-time F1-region in mid-latitude Europe, on CD-Proceedings of the 2nd COST 271 Workshop, 2-4 October 2002, Faro, Portugal, WG 3, P04_3.

BošKa, J. and D. PANChEVA (1989): Ionospheric effects of extreme solar activity of February 1986, Handbook for MAP, 29, 231-235.

Bourdillon, A., C. Haldoupis and J. Delloue (1995): High-frequency Doppler radar observations of magnetic aspect sensitive irregularities in the mid-latitude $E$-region ionosphere, $J$. Geophys. Res., 100, 21503-21521.

Bowman, G.G. (1981): The nature of ionospheric spread- $F$ irregularities in mid-latitude region, J. Atmos. Terr. Phys., 43, 65-79.

BowmAn, G.G. (1990): A review of some recent work on mid-latitude spread- $F$ occurrence as detected by ionosondes, J. Geomag. Geoelectr., 42, 109-138.

Buonsanto, M.J. (1999): Ionospheric storms - A review, Space Sci. Rev., 88, 563-601.

BuREŠOvÁ, D. (2002): Effect of geomagnetic storms on the $F 1$-region electron density at European mid-latitudes, in EGS, $S T 2$, Nice, France (invited paper).

BuREŠOvÁ, D. and J. LAŠTOVIČKA (2001): Changes in the F1-region electron density during geomagnetic storms at low solar activity, J. Atmos. Sol.-Terr. Phys., 63, 537-544.

BuREŠOvÁ, D. and J. LAŠTOVIČKA (2002): Electron density in the F1-region over Europe and geomagnetic storms, in COSPAR 02-A-00163, Huston, U.S.A.

BuREŠOVÁ, D. and J. LAŠTOVIČKA (2003a): Geomagnetic storm and F1-region over Europe, in Proceedings of the 3rd COST 271 Workshop, 23-27 September 2003, Spetses, Greece.

BUREŠOVÁ, D. and J. LAŠTOVIČKA (2003b): Height profile of intense geomagnetic storm effects on ionospheric $F$-region at European middle latitudes, in IUUG Symposium, Sapporo, Japan.

BuREŠOVÁ, D. and J. LAŠTOVIČKA (2003c): Height profile of the effects of geomagnetic storm on the $F$-region of the ionosphere over Europe, in $E G S-A G U-E U G$, Nice, France.

Burešová, D., J. LaštoviČKa, D. Altadill and G. Miro (2002a): Daytime electron density at the F1-region in Europe during geomagnetic storm, Ann. Geophysicae, 20, 1-15.

Burešová, D., J. Boskova, J. LAŠtovičKa, D. Altadill, D. Novotna and G. Miro (2002b): Latitudinal differences in the $F 1$-region response to geomagnetic storm over Europe, in EGS, ST9, Nice, France.

Burešová, D., J. Laštovička, I. Stanislawska, D. Altadill, G. Miro, E. Turunen and T. Ulich (2002c): Seasonal variation of the $F 1$-region response to geomagnetic storms over Europe, on CD-Proceedings of the 2nd COST 271 Workshop, 2-4 October 2002, Faro, Portugal, WG 1, P09_1.

Edwards, K.J., L. Kersley and L.F. Shrubsole (1984): Sporadic E propagation at frequencies around $70 \mathrm{MHz}$, Radio Electron. Eng., 54, 231-237.

Fukao, S., J.P. McClure, A. Ito, T. Sato, I. Kimura, T. Tsuda and S. Kato (1988): First VHF radar observations of mid-latitude $F$-region field aligned irregularities, Geophys. Res. Lett., 15, 768-771.

Haldoupis, C., A. Bourdillon, M. Six and J. Delloue (1996): Mid-latitude E-region coherent backscatter at two HF radar frequencies, J. Geophys. Res., 101, 7961-7971. 
Kelley, M.C. (1989): The Earth's Ionosphere (Academic Press, San Diego).

KING, G.A.M. (1961): Analysis of the F1-F2 transition region, J. Geophys. Res., 66, 2757-2762.

KLEVANS, E.H. and G. IMEL (1978): E-region coupling effects on the Perkins spread- $F$ instability, J. Geophys. Res., 83, 199-202.

LAŠTOVIČKA, J. (1996): Effects of geomagnetic storms in the lower ionosphere, middle atmosphere and troposphere, J. Atmos. Terr. Phys., 58, 831-843.

Maruyama, T. (1990): Instability in the F-region in the low- to mid-latitudes, Planet. Space Sci., 38, 273-285.

Mikhailov, A.V. and K. Schlegel (2003): Geomagnetic storm effects at F1-layer heights from incoherent scatter observations, Ann. Geophysicae, 21, 583-596.

Perkins, F.W. (1973): Spread-F and ionospheric currents, J. Geophys. Res., 78, 218-226.

PRÖLSS, G.W. (1995): Ionospheric F-region storms, in Handbook of Atmospheric Electrodynamics, edited by H. Volland (CRC Press, Boca Raton, FL), vol. 2, 195-248.

Richmond, A.D., M. Blanc, B.A. Emery, R.H. Wand, B.G. Fejer, R.F. Woodman, S. Ganguly, P. Amayenc, R.A. BehnKe, C. CAlderon and J.V. Evans (1980): An empirical model of quiet-day ionospheric fields at middle and low latitudes, J. Geophys. Res., 85, 4658-4664.

Rishbeth, H. and O.K. GARRIOTT (1969): Introduction to Ionospheric Physics (Academic Press, New York and London).

Whitehead, J.D. (1961): The formation of the sporadic E-layer in the temperate zones, J. Atmos. Terr. Phys., 20, 49-58. 